\title{
ARTE CONTEMPORÂNEA E O RETORNO DA CENSURA: CASO QUEERMU- SEU E SUAS ADJACÊNCIAS ${ }^{1}$
}

\author{
Arte contemporáneo y el regreso de la censura: el caso QueerMuseu y sus adyacencias \\ Contemporary art and the return of the censorship: the QueerMuseum case and its \\ adjacencies
}

Jacks Ricardo Selistre', Mariana Duarte ${ }^{2}$

\begin{abstract}
Resumo
O presente estudo tem como principal objetivo realizar uma análise da censura no panorama artístico brasileiro, focando na exposição QueerMuseu: Cartografias da Diferença na Arte Brasileira, que foi precocemente fechada em Porto Alegre no ano de 2017. Busca-se compreender de que maneira a história da arte foi construída, relacionando com as imposições sistêmicas que levam à construção e à manutenção de um cânone que rege a instituição da arte, deste modo analisa-se como ocorrem as exclusões presentes no sistema de arte hegemônico, perpassando pela questão da censura, em sua origem no Brasil de 1964, até os dias atuais. Ainda realiza-se uma análise sobre os tipos de censura possíveis nas sociedades contemporâneas, explorando desde as censuras governamentais às censuras que são desenvolvidas socialmente através dos discursos.
\end{abstract}

Palavras-chave: QueerMuseu; Censura; Arte Queer; Liberdade de Expressão.

\section{Resumen}

El presente estudio tiene como objetivo realizar un análisis de la censura en el panorama artístico brasileño, enfocando en la exposición QueerMuseu: Cartografias da Diferença na Arte Brasileira, que fue cerrada tempranamente en Porto Alegre en el año de 2017. Se busca comprender de que manera la historia del arte fue construida, relacionando con las imposiciones sistémicas que llevan a la construcción y a la mantención de un canon que comanda la institución del arte, de este modo se analiza como ocurren las exclusiones presentes en el sistema del arte hegemónico, problematizando la cuestión de la censura, desde su origen en el Brasil de 1964, hasta los días actuales. Aún se realiza un análisis sobre los tipos de censura posibles en las sociedades contemporáneas, explorando desde las censuras gubernamentales a las censuras que son desarrolladas socialmente a través de los discursos.

Palabras-clave: QueerMuseu; Censura; Arte Queer; Libertad de Expresión.

\begin{abstract}
The main objective of this study is to analyze censorship in the Brazilian artistic scene, focusing on the exhibition QueerMuseu: Cartographies of Difference in Brazilian Art, which was early closed in Porto Alegre in 2017. It seeks to understand how the history of art was built, relating to the systemic impositions that lead to the construction and maintenance of a canon that governs the institution of art, thus analyzing how the exclusions present in the hegemonic art system occur, through the question of censorship, in its origin in Brazil from 1964, to the present day. An analysis is still made of the types of censorship possible in contemporary societies, ranging from government censorship to censorship that is socially developed through discourses.
\end{abstract}

Keywords: QueerMuseum; Censorship; Queer Art; Freedom of Expresion.

\footnotetext{
1 É doutorando em Artes Visuais pelo Programa de Pós-Graduação em Artes Visuais da Universidade Federal do Rio Grande do Sul. É mestre em Artes Visuais pelo Programa de Pós-Graduação em Artes Visuais da Universidade Federal de Santa Maria (2018).

2 É doutora em Letras, na área de Processos Culturais, pela Universidade de Caxias do Sul. É Mestra em Letras, Cultura e Regionalidade.
} 


\section{Introdução}

As expressōes artísticas que fogem aos ideais hegemônicos apareceram sutilmente em exposiçōes durante o século XX e apesar de ultimamente terem sido mais exploradas, ainda possuem uma presença tímida no panorama global. Diante desta situação, o presente artigo busca fazer uma breve análise da exposição QueerMuseu: Cartografias da Diferença na Arte Brasileira. O sistema artístico pode ser compreendido como fruto de uma construção eurocêntrica, branca, masculina e heterossexual, e sendo a estes destinada. Deste modo, percebe-se a existência de uma regulamentação da produção artística e das exposiçōes, criando um discurso que se posiciona como universal, mas que atua como um discurso e uma história das particularidades (LOPONTE, 2002). Assim, nota-se a existência de dispositivos de poder que operam de diferentes formas através do sistema artístico, fundamentado pelas instituições que o compõem, como o museu, a crítica e a história da arte, ou bem, através de discursos. Os modos de regulação artística podem desencadear um processo recorrente durante a ditadura militar brasileira: a liberdade de expressão, artística e de pensamento foram restringidas por censores.

Segundo Olivieri (2008), podemos compreender que a censura, instaurada durante o Regime Militar traduzia-se em uma espécie de exame a que eram submetidos trabalhos artísticos ou informativos, com base em critérios morais e/ou políticos. Foram criadas leis para tal ação, como, por exemplo, o caso da censura na mídia, que segundo o Decreto-Lei $n^{\circ} 1.077$, de 21 de janeiro de 1970 instituiu a censura prévia, exercida de tal modo: uma equipe de censores instalava-se permanentemente na redação dos jornais, para decidir o que poderia ou não ser veiculado, feito que gerava desconforto, inibição e divergências entre os profissionais da área - no caso da arte o processo tinha o mesmo viés.

O historiador Antonio Gasparetto Jr. (2010) aponta que havia temor devido as consequências ocorridas com quem voltava-se contra a Ditadura, visto que artistas e intelectuais a partir de 1970 viam-se diante do crescimento da perseguição política, que se manifestava por sequestros, prisão, tortura e assassinatos. Assim, pode-se perceber que a censura se articula atraves do poder governamental e tambem através de discursos autoritários, amedrontadores e hostis.

Diferente da censura governamental, os mecanismos sociais de censura se estabelecem através dos discursos. Há que salientar a pluralidade de discursos existentes, podem haver os que geram opiniáo e discussăo sobre a questao artística, formando um debate aberto e o cambio de ideias, assim como também existem os discursos moralistas, que não geram altercaçáo, mas simplesmente questionam de modo iredutivel a produçáo e o comportamento artistico e midíatico. Um discurso moralista quando reiterado e difundido, pode, muitas vezes, distorcer a produçăo artistica em questão, de modo 列 truída por grupos pollticos/sociais. A distorçăo e o exagero relacionado a tematicas polemicas possibilitam uma espécie de pânico social emoral, que atraves das falas autontanias tem a tendencia a desencadear mecanissmos sociais de censu Dessa maneira, as obras de arte e os conteúdos jornalisticos dependeriam dos valores morais advindos da sociedade.

Os discursos autoritários (re)surgem, os valores morais parecem estar sendo subvertidos pela arte, a qual, de acordo com essas preleçoes infundamentadas, ataca o bem comum, os valores de nossa sociedade, bem como possibilita inumeros pensamentos que descontextualizam a produção artística. Apesar do distanciamento histórico do ano de 1985, dito o término do período ditatorial, os discursos autoritários estão à tona no Brasil, resgatando muitas vezes a censura.

O conservadorismo ataca novamente, consequência disso foi o fechamento antecipado da exposição QueerMuseu: Cartografias da Diferença na Arte Brasileira, com curadoria de Gaudêncio Fidelis e também, mais tarde, o Museu de Ar Moderna de São Paulo foi atacado por sediar a performance que envolvia nudez do artista carioca Wagner Schwartz.

As mostras referidas acima geraram grandes polêmicas no circuito social e político do Brasil. Foram acusaçōes de que a arte não deve abordar temas controversos e delicados e que deveria concentrar-se no belo, sugerindo um retorno a épocas como o Renascimento, onde estava baixo tutela do Estado e da lgreja. Os novos críticos de arte se esquecem que a história da arte se serviu incontáveis vezes das temáticas desagradáveis, que fogem de temas corriqueiros para abordar assuntos complexos e por vezes chocantes e perturbadores. A exposição QueerMuseu certamente não é a primeira a abordar sexualidades na arte, desde os primórdios artistas se interessam pelo comportamento sexual e afetivo, de maneira metafórica ou não.

Assim, é importante frisar que a arte envolve crítica, distanciamento e interpretação, ela se encontra embasada na história, na filosofia, no questionamento e discernimento, não admitindo discursos autoritários e nem verdades absolutas, frente aos problemas antigos ou contemporâneos, a fim de levar a reflexão e não a verdades absolutas.

\section{O Cânone Artístico Ocidental}

A história da arte se articulou através dos estudos e de modelos hegemônicos. Por hegemônicos entende-se aquilo que é dominante, idealizado como superior. Estes ideais canônicos foram construídos e destinados ao homem e pelo ho-

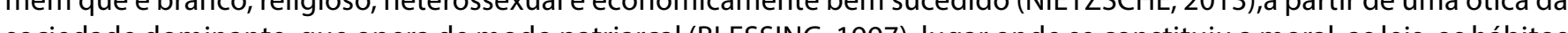
sociedade dominante, que opera de modo patriarcal (BLESSING, 1997), lugar onde se constituiu a moral, as leis, os hábitos e também o sistema da arte. Para Clifford Geertz (1999), o sistema da arte vai além de sinais e símbolos e inclusive pode e deve ir além de ser um puro meio de comunicação, ou seja, falamos aqui de formas de pensamento.

Para entender melhor, compreende-se que esse sistema é criado por este grupo e é endereçado a eles, não abrindo espaço às diferenças. Como mostra Michel Foucault (2002), o imaginário do ideal não possui origem, visto que foi inventado pelo ser humano através de uma série de mecanismos, e influenciado por obscuras relaçōes de poder. Em poucas ocasiōes na história da arte se percebe a abertura do sistema àqueles que contrariam essas regras. Assim, a genealogia do sistema mostra que a história da arte é composta por exclusões (ARNOLD, 2004) e os excluídos/as são principalmente aqueles/ as que fogem às normas impostas.

Igualmente, criam-se histórias paralelas à História da Arte considerada universal, permitindo a insurgência de outras subjetividades que não foram contempladas até então. Conhecida como "História Oficial", a corrente privilegia a autoria de grandes nomes do intelecto, valoriza os "heróis" e os "grandes mestres", sendo reproduzida pelos livros didáticos. Estas publicações, por sua força, usualmente aparecem em primeiro plano, mas é preciso realizar uma reflexão e acolher na mentalidade que histórias paralelas também existem quando se diz respeito à arte produzida por mulheres, por negros/ as, ou por sujeitos não-heterossexuais.

Diante do exposto, é perceptível que o sistema artístico atua como um jogo de manobras que converge ao interesse hegemônico, impedindo que os renegados/as consigam adentrar às narrativas e aos espaços considerados universais, como os museus.

\section{A Subversão Da Hegemonia Artística}

Os processos de imposição comportamental são comuns em nossa sociedade, se reiteram e se repetem ao mesmo Ao contraver os no ordem exógena, fazendo com que o sujeito siga essas convençoes, ou venha a contraverte-las. Ao contraverter os modelos socialmente aceitos, os indivíduos exploram as brechas do sistema, possibilitando assim novas subjetividades e também novas leituras. Como consequencia da contravenção à norma surgem outras possibilidades de leitura e de interpretação.

Para Peter Burke (2004), uma particular e significante vantagem da arte visual é que a imagem pode comunicar rápida e enfaticamente os detalhes de algum processo complexo. O pensamento permite-se a qualquer tipo de fruição, sem estar dependente de um conjunto de normas que engessa a refexăo.

Neste sentido, vê-se a existência de inúmeros outros cenários em que as obras de arte podem se apresentar, bem como se servir de diferentes contextos que náo iguram no modelo idealizado. Ao náo seguir o cânone artistico surgem discursos artisticos pautados na hegemonia do sistema ena tradiçao das linguagens attisticas, bem como discursos moralistas que con as de arte, desconsiderando valores esteticos e conceituals, excluindo o caráter crítico-reflexivo das obras de arte. Os discursos conservadores autoritários aparecem frequentemente em nossa sociedade, ainda mais no cenário atual, onde forças conservadoras e autoritárias ganham poder em nivel nacional e global (CANCLINI, 2008).

Versa-se se uma obra pode ser considerada arte pois ela questiona a supremacia da tradição cristã, pois aborda comportamentos sexuais dissidentes - os quais existem em nossa sociedade, mas geralmente não são abordados, sendo frequentemente omitidos e escondidos por serem tabus sociais. Este pensamento faz com que as obras em questão sejam polêmicas, destacando-as através da subversão de valores morais e desvinculando-as de uma análise plural e de seu contexto a fim de desvalorizar sua potencia conceltual, trazendo-as meramente como ataques ao sistema de valores da nossa sociedade. Deste modo determinadas obras e comportamentos geram pânico social, devendo ser combatidas em prol de uma suposta normalidade. A manipulação do significado das obras de arte tem sido frequente, sendo ação de grupos autoritários, os quais alegam que determinadas produções que abordam temáticas polêmicas como obras que atentam aos bons costumes da sociedade ou até mesmo como obras criminosas.

Frente a esses diálogos conservadores temos o pensamento estético. A obra está aberta a leituras (ECO, 2013), o público irá fruir a obra de arte e construirá cada um/a a sua própria leitura, de acordo com as suas próprias vivências e conforme a sua bagagem cultural. Se para algum espectador determinada obra faz apologia a determinado crime esta é a sua leitura, isso nao quer dizer que o/a artista da obra pense dessa maneira, nem que a obra tenha esse significalo. Sabe se que a obra de arte não está intencionada em incitar comportamentos maldosos, mas atua de diversas maneiras em diversos contextos como crítica ao comportamento da sociedade.

Ao fruir obras polêmicas o/a espectador/a tem que estar preparado/a para tal. A leitura, a interpretação e a obra devem ser levadas à discussão, mostrando que existem inúmeras posições acerca de uma mesma imagem. O que possibilita a reflexăo, ao compreender a interpretaçao de outrem percebe-se que a obra não se encontra isolada em uma determinada leitura, mas que possui uma multiplicidade de sentidos.

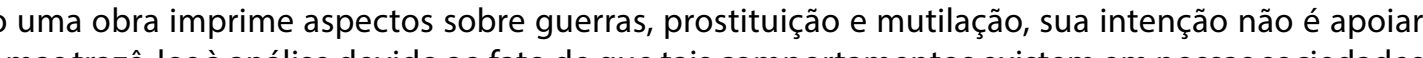
esses comportamentos, mas trazê-los à análise devido ao fato de que tais comportamentos existem em nossas sociedades 

e que possamos refletir sobre o que não é dito, explorando outras percepções subjetivamente. A função é que se perceba
e que se reflita sobre o que não está em pauta, sobre o que é desagradável para qualquer espectador/a. Seu impacto, sua agressividade não a tornam menos arte por isso. Na arte contemporânea o objeto se associa com as possibilidades conceituais e interpretativas.

Ao contemplar uma obra de arte, deve-se considerar o seu contexto e não impor o um conceito fechado de arte em uma obra que subverta o cânone. Ao deslocar uma obra de seu contexto artístico devemos ter cautela, pois seu significado pode também ser deslocado, como temos visto nas polêmicas geradas pela exposição QueerMuseu: Cartografias da Diferença na Arte Brasileira. Ressignificar uma obra de arte não se constitui em um erro, visto que a obra deve ser livremente interpretada e apreciada. É importante não fazer com que opiniōes e discursos não descontextualizem a produção. Para isso é necessário conhecimento da história da arte e de suas manifestações.

Reitera-se as palavras de Eco (2013) no que diz respeito a fruição:

A poética da obra "aberta"tende, como diz Pousser, a promover no intérprete "atos de liberdade" consciente, pô-lo como centro ativo de uma rede de relaçōes inesgotáveis, entre as quais ele instaura sua própria forma, sem ser determinado por uma necessidade que Ihe prescreva o modo definitivo de organização da obra fruída; mas [...] poder-se-ia objetar que qualquer obra de arte, embora não se entregue inteiramente inacabada, exige uma resposta livre e inventiva, Imente compreendida se o intérprete não a reinventar num ato de congenialidade com o autor. (ECO, 2013, p. 41)

Ao olhar para a obra Guernica de Pablo Picasso, pintada em 1937, não poderia-se dizer "é uma crítica as touradas espanholas", pois, por mais que figurem touros e pessoas agonizando, essa obra trata sobre a guerra. Tampouco seria adequado dizer que é uma obra que faz apologia à guerra, visto que o artista a realizou como uma crítica à Guerra Civil Espanhola (1936-1939) e a todos os tipos de violência, de maneira que a obra inscreve-se no marco da liberdade, possuindo assim um olhar crítico aos regimes autoritários.

Torna-se dificil compreender uma obra sem que se conheça a intenção do/a artista, pode-se ter uma leitura autônoma em relaçáo a intenção de quem a produziu. Entretanto náo e possivel, a partir de leituras infundamentadas e manipuladas, afirmar que o/a artista tinha essa intenção. Ao realizar isso, deturpa-se o contexto e o real significado da obra, excluindo possibilidades subjetivas coerentes.

\section{Censura Contemporânea}

Antiga conhecida de artistas e jornalistas que viveram a Ditadura Militar no Brasil, a censura reaparece através de novas faces. Não mais governamental, mas social. Influenciada por discursos autoritarios e desestruturados quanto ao conhecimento da historia da arte. A exposiçăo QueerMuseu. Cartografias da Diferença na Arte Brasileira foi a primeira a ser atacada em 2017. Grupos políticos e religiosos atacaram veementemente a mostra que abordava questoes relacionadas à sexualidade e ao gênero, suas justificativas eram que as obras incitavam a intolerancia religiosa e a crimes hediondos. Através da mobilização social esses grupos conseguiram o encerramento antecipado da exposição sediada pelo Santander Cultural, o qual desculpou-se por causar desconforto em espectadores, decidindo encerrar a exposição já que algumas de suas obras "desrespeltavam simbolos, crenças e pessoas", de maneira que, de acordo com a instituiçăo "quando a arte não é capaz de gerar inclusão e reflexão positiva, perde seu propósito maior, que é elevar a condição humana"2. Assim o Santander Cultural deciduu encerrar a exposição antes do prazo previsto, o que acarretou uma série de manifestações por parte da classe artistica, que alegava se tratar de um episodio de censura. Ao ser pressionado a se encerrar uma exposição, vê-se que as forças conservadoras se reestruturam, buscando calar artistas e limitar seu campo de atuação.

Ademais dos discursos questionando o caráter artístico das obras em exposição, houve também aqueles que alegaram que ela cometia ou incitava crimes. Baseando-se nessas denúncias, o Ministério Público enviou um promotor de Justiça da Infância e da Juventude de Porto Alegre para averiguar a existência de crime na exposição, o qual afirmara a inexistência de infrações na referida mostra ${ }^{3}$.

Pouco depois da polêmica da QueerMuseu, a performance La Bête, de Wagner Schwartz, foi duramente criticada por ativistas conservadores. A performance consistia no artista nu deitado no chão do Museu de Arte Moderna de São Paulo, a performance tratava de uma citaçăo às obras Bichos da artista Lygia Clark. Assim o artista entregava seu corpo para que fosse manipulado como os bichos propostos por Clark ainda na década de 70. A polemica baseou-se em uma fotografia, onde uma criaça aparecécando pera proporciona arte poonogafca sexual pa o publico. É 2 Anota sobrea exposiçao encontra-se disponivel por meio de nota no Facebook da instituiçăohttps://www.facebook.com/SantanderCultural/ posts/732513686954201 acesso: 10 de out. de 2017

noticia: https://www.mprs.mp.br/noticias/45185/ acesso: 10 de out. de 2017 reservada do museu, onde havia uma indicação etária e informando que a performance continha nudez. A criança estava no museu acompanhada da mãe, a qual autorizou sua presença e a interação com o performer. A situação saiu do controle, grupos escandalizaram a performance, descontextualizando-a e tratando-a como sexual - sendo apenas nudez artistica. O MAM, diferentemente do Santander Cultural, posicionou-se sobre o acontecido, defendeu o trabalho e denunciou os casos de intimidação verbal, patrimonial e física que a instituição sofrera. A instituição evidenciou que a performance ocorria em sala separada, com indicação etária e informação sobre a nudez artística, ainda informou que na performance não havia nenhum conteúdo erótico ou sexual, o que acontecia era a interação espontânea e livre do públicớ. Ao posicionar-se a instituição fortaleceu o diálogo, não se sujeitando a discursos sem embasamento, mostrando a potência dos espaços de arte inscritos em uma sociedade democrática.

Visto o momento o qual nos encontramos, a exposição Histórias da Sexualidade sediada no Museu de Arte de São Paulo também foi alvo de críticas antes mesmo de sua abertura. Esta exposição possuia uma classificação indicativa, proibindo o ingresso de menores de dezoito anos ao espaço expositivo. A montagem buscou discutir questões de gênero, sexualidades e feminismos na arte, proporcionando assim debates inclusivos, plurais e relevantes para a sociedade (MARTINS, 2017). Percebe-se a intenção de conscientizar sobre este assunto, em hipótese alguma a exposição propõe a erotização ou a sexualização, a intenção é gerar o pensamento crítico frente às sexualidades, aos preconceitos, ao machismo e à cultura do estupro. Muitas das obras expostas não possuem conteúdo sexual explícito. A indicação de idade talvez foi pensada pela equipe curatorial, por conta da polêmica gerada pela exposição QueerMuseu.

A censura não é caminho viável para uma sociedade democrática, a arte possui a liberdade, joga com ela a fim de questionar e muitas vezes de perturbar. Náo e a primeira vez que exposiçoes são censuradas, certamente náo seráo as últimas. A utilização para a argumentaçăo deste estudo através dos exemplos anteriores, vai ao encontro do pensamento de Wanner (2010), que coloca que é possivel observar que o pensamento de imagens fora de um contexto cultural provoca ambiguidades irreparáveis para a fruição e contemplação da arte, visto que nenhuma imagem era feita sem uma determinada função.

A guisa de encerramento, o presente estudo buscou trazer um breve percurso pela censura e pela sua reincidência no contexto brasileiro da arte, trazendo olhares estrangeiros as exposiçoes. Tem-se visto que as minorias tem sido mais abordadas na arte contemporánea, contudo, há que ficar atento quanto ao tratamento que ela recebe. Visto que muitas vezes ela pode ser manipulada por discursos que fogem do campo das artes. De encontro a isto, percebe-se na atual conjuntura uma onda de interpretações precipitadas, errôneas e infundamentadas está assemelhando-se à censura de décadas passadas, que acreditava-se já extinta.

A censura proíbe o pensamento livre, cerceia as artes e impossibilita a expressão. Em contrapartida, inúmeros/as artistas desenvolveram técnicas para driblar a censura. Criando obras ilegiveis, incompreensiveis e cuja linguagem não podia ser que eram ilegiveis. Ou bem, como Chico Buarque de Holanda, que burlou o sistema de vigilância enviando suas músicas à censura figurando o nome de outro músico. Buarque usou desta artmanha pois em um determinado momento percebeu-se que quando enviava qualquer material para ser analisado, eles eram prontamente descartados por serem de sua autoria. Comprendese que a ateér. é proibida ela encontra outra alternativa de dizer o que quer, de dizer o que querem calar. A arte subverte as limitações, transcende o visível, problematiza questões sociais e permite críticas subjetivas a temáticas complexas.

\section{REFERÊNCIAS}

ARNOLD, Dana. Art History: a very short introduction. Oxford: Oxford Press, 2004.

BLESSING, Jennifer. Rose is a Rose is a Rose. In: ___ . Rose is a Rose is a Rose: Gender Performance in Photography. New York: Solomon R. Guggenheim Museum, 1997, p 31.

BURKE, Peter. Testemunha ocular: história e imagem. Bauru: EDUSC, 2004.

CANCLINI, Néstor García. Latino americanos à procura de um lugar neste século. São Paulo: Iluminuras, 2008.

ECO, Umberto. A obra aberta. São Paulo: Perspectiva, 2013.

4 Nota de posicionamento disponivel em: https://www.facebook.com/MAMoficial/posts/1744628062234900 acesso em 10 de dez. de 
FOUCAULT, Michel. A verdade e as formas jurídicas. Rio de Janeiro: Nau Editora, 2002.

GASPARETO JUNIOR, Antonio. Desaparecidos políticos. 2010. Disponível em: <http://www.historiabrasileira.com/ ditadura-militar/desaparecidos-politicos>. Acesso em: jan. de 2018.

GEERTZ, Clifford. O Saber Local. Petrópolis: Vozes, 1999.

LOPONTE, Luciana Gruppelli. Sexualidades, artes visuais e poder: pedagogias visuais do feminino. Estudos feministas, p. 283-300, 2002.

MARTINS, Heitor. Histórias da Sexualidade no MASP. In: PEDROSA, Adriano; BECHELANY, Camila (org.). Histórias da Sexualidade: Antologia. São Paulo: MASP, 2017.

NIETZSCHE, Frederich. Genealogia da Moral. São Paulo: Escala, 2013.

OLIVIERI, Antonio. Censura: 0 regime militar e a liberdade de expressão. 2008. Disponível em: https://educacao.uol. com.br/disciplinas/historia-brasil/censura-o-regime-militar-e-a-liberdade-de-expressao.htm acesso em: 13 de nov. de 2017.

WANNER, M. C. A. Paisagens sígnicas: uma reflexão sobre as artes visuais contemporâneas [online]. Salvador: EDUFBA, 2010. 